\title{
Hasil Keterampilan Lempar Lembing (Studi Eksperimen Menggunakan Alat Bantu Bola Berekor Pada Mahasiswa)
}

\author{
Javelin Throw Skills (Experimental Study using a Ball-Based Aid Tool)
}

\author{
Akhmad Sobarna, Sandi Dwi Triono \& Agus Supratman \\ STKIP Pasundan, Cimahi, Jawa Barat, Indonesia \\ Akhmadsobarna9@gmail.com
}

Naskah diterima tanggal 16/01/2019, direvisi akhir tanggal 22/04/2019, disetujui tanggal 30/04/2019

\begin{abstract}
Abstrak
Belajar lempar lembing melalui media bola berekor. Penelitian ini berjenis penelitian eksperimen dengan Subjek penelitian adalah mahasiswa kelas tingkat dua STKIP Pasundan Cimahi Tahun Ajaran 2017/2018 dengan jumlah 60 mahasiswa yang dibagi menjadi dua kelas yaitu kelas kontrol dan kelas non kontrol. Data dikumpulkan melalui hasil post-test dan pre-test, dan rubrik penilaian untuk menilai keterampilan dan hasil belajar. Data dianalisis dengan metode analisis statistik deskriptif kuantitatif berbantu aplikasi SPSS-20. Hasil analisis menunjukkan bahwa ada peningkatan proses dan hasil belajar pada pembelajaran lempar lembing di STKIP Pasundan Cimahi.

Kata kunci: bola berekor, keterampilan lempar lembing

Abstract

Learning to javelin throw through tailed ball media. This research was a type of experimental research with the research subjects being the second-grade students of STKIP Pasundan Cimahi Academic Year 2017/2018 with the number of 60 students divided into two classes, namely control class and non-control class. Data was collected through the results of post-test and pre-test, and assessment rubrics to assess skills and learning outcomes. Data were analyzed using quantitative descriptive statistical analysis method with SPSS-20 application. The results of the analysis showed that there was an increase in the learning process and results in javelin throwing learning in STKIP Pasundan Cimahi.
\end{abstract}

Keywords: tailed ball, javelin throw skills

\section{PENDAHULUAN}

Dalam pelaksanaan program pendidikan jasmani menghendaki adanya suatu perubahan pada diri peserta didik, perubahan baik dalam hal kematangan fisik, psikis maupun keterampilannya. Maka demi munculnya perubahan tersebut tidak hanya dibutuhkan suatu strategi yang handal saja namun juga keberadaan sarana dan prasarana pendidikan yang terdapat didalam suatu lingkungan pendidikanpun menjadi sesuatu yang sangat penting demi membantu terciptanya keberhasilan dalam menimbulkan adanya perubahan kematangan fisik, psikis maupun keterampilan yang dimiliki oleh peserta didik.

Menurut Sukadiyanto penjasorkes memiliki dua pengertian, yaitu (1) pendidikan untuk jasmani, dan (2) pendidikan melalui aktivitas jasmani. Pendidikan untuk jasmani mempunyai pengertian bahwa pendidikan bertujuan untuk meningkatkan kualitas jasmani, misalnya: kekuatan, daya tahan (stamina), kecepatan (speed), kelincahan (agility), koordinasi, keseimbangan (balance), dan sebagainya. 
Dalam pembelajaran yang berkaitan dengan aktivitas fisikpun mahasiswa diharapkan mampu terlibat secara aktif baik dalam aspek kognitif, afektif dan psikomotor, dalam penelitian ini aktivitas fisik yang dimaksud adalah aktivitas fisik dalam pembelajaran olahraga atau yang kerap kali disebut dengan pendidikan jasmani olahraga dan kesehatan. Lamusu (2011) menyatakan bahwa "Pendidikan jasmani olahraga dan kesehatan merupakan suatu proses pendidikan yang proses pelaksanaan pembelajarannya melalui aktivitas fisik dan bertujuan tidak hanya untuk mencapai tingkat kebugaran semata melainkan aspek kognitif dan afektif menjadi sasaran dari pada pembelajaran pendidikan jasmani olahraga dan kesehatan itu sendiri".

Jika dikaitkan dengan pembelajaran atletik ketiga aspek tersebut ternyata sangatlah dibutuhkan tidak hanya dalam aspek psikomotoriknya saja namun juga dalam aspek afektif dan aspek kognitifnya pun harus diperhatikan. Seperti yang kita ketahui bahwa atletik merupakan aktivitas jasmani yang kompetitif atau dapat dilombakan, meliputi beberapa nomor yang terpisah berdasarkan kemampuan gerak dasar manusia.

Dalam penelitian ini peneliti ingin melihat lebih jauh mengenai keterampilan gerak dasar lempar lembing pada mahasiswa secara umum. Subjek dari penelitian ini adalah mahasiswa STKIP Pasundan Cimahi. Berdasarkan pada hasil observasi awal, peneliti mendapati permasalahan yang berkaitan dengan kurangnya keterampilan dasar lempar lembing yang dimiliki oleh mahasiswa Stkip Pasundan Cimahi dan menurunnya hasil belajar yang diperoleh dalam pelaksanaan pembelajaran lempar lembing. Maka karena hal tersebut peneliti berupaya untuk dapat memberikan inovasi demi meningkatkan keterampilan dan hasil belajar mahasiswa terutama dalam nomor atletik lempar lembing. Sehingga terbentuknya judul penelitian yakni "Hasil Keterampilan Lempar Lembing (Studi Eksperimen) Menggunkan Alat Bantu Bola Berekor Pada Mahasiswa".

Untuk mewujudkan tujuan pembelajaran tersebut tentunya membutuhkan media atau alat bantu pembelajaran sperti adanya modifikasi alat pembelajaran, dimana media atau alat bantu yang dimodifikasi merupakan alat untuk menyampaikan pesan atau bahan ajar kepada peserta didik yang didalamnya terdapat rangsangan atau interaksi yang akan diterima oleh peserta didik sehingga terciptanya proses belajar mengajar. Seperti yang diungkapkan oleh Sobarna (2017) bahwa "media merupakan proses interaksi yang dilakukan guru dengan muridnya, proses tersebut dapat melibatkan media sebagai alat bantu untuk lebih mempermudah proses interaksi yang dilakukan". Hal tersebut sejalan dengan yang di ungkapkan oleh Rizky (2013) bahwa "Media merupakan alat untuk merangsang pikiran, perasaan, kemauan sehingga dapat mendorong terjadinya proses belajar". Media yang di gunakan untuk membantu proses pembelajaran yaitu dengan menggunakan bola berekor, seperti yang ungkapkan oleh Hasan (2015) "Bola berekor merupakan bola yang sudah dimodifikasi dengan ditambahkan ekor yang aman untuk digunakan dalam permainan".

Media yang telah dimodifikasi adalah sebagai langkah untuk memperoleh kepuasan dan keberhasilan dalam proses pembelajaran, hal tersebut seperti yang diungkapkan oleh Yoyo (2015) bahwa "Modifikasi dalam mata pelajaran pendidikan jasmani diperlukan dengan tujuan agar mahasiswa memproleh kepuasan dalam mengikuti pelajaran serta meningkatkan kemungkinan keberhasilan dalam berpartisipasi dan siswa dapat melakukan pola gerak secara benar”. Dengan 
adanya alat bantu yang berupa alat yang dimodifikasi ini ternyata berdampak baik bagi kepuasan mahasiswa melakukan proses pembelajaran. Hal tersebut sejalan dengan tujuan yang diungkapkan oleh Lutan (2015) bahwa "modifikasi dalam mata pelajaran pendidikan jasmani diperlukan dengan tujuan agar:"

1) Siswa memperoleh kepuasan dalam mengikuti pelajaran

2) Meningkatkan kemungkinan keberhasilan dalam berpartisipasi

3) Siswa dapat melakukan pola gerak secara benar.

Penelitiaan ini didukung oleh beberapa penelitian lain yang telah dilakukan sebelumnya yakni seperti penelitian yang dilakukan oleh Haryono (2016) penelitian tersebut bertujuan untuk mengetahui peningkatan hasil belajar lempar lembing melalui modifikasi pembelajaran bola berekor yang menggunakan jenis penelitian tindakan kelas. Penelitiaan yang telah dilakukan tersebut ternyata dapat meningkatkan hasil belajar siswa pada setiap siklusnya. Hal tersebut sejalan dengan penelitian yang dilakukan oleh Subari (2013) menyatakan bahwa melalui modifikasi alat pembelajaran dapat meningkatkan gerak dasar lempar lembing serta bertujuan untuk memperbaiki dan meningkatkan pembelajaran gerak dasar lempar lembing hingga tercapainya keberhasilan dalam proses pembelajaran. Kedua penelitian tersebut ternyata di perkuat kembali dengan penelitian yang dilakukan oleh Hasan (2014) bahwa penelitiaan ini bertujuan untuk mengetahui peningkatan hasil belajar lempar lembing hingga tercapai keberhasilanya, adapun mengenai hasil dari penelitian ini adalah pada siklus I dengan mengguakan alat bole berekor tercapai prosentasi ketuntasan belajarnya adalah mencapai $64,7 \%$ kemudian pada siklus II ternyata menunjukan adanya peningkatan menjadi 85,3\%. Maka penelitian yang telah dilakukan tersebut dapat dijadikan sebagai sumber pendukung atas berlangsungnya penelitian ini karena adanya persamaan tujuan yakni sama-sama ingin meningkatkan hasil dan keterampilan gerak dasar lempar lembing.

\section{METODE PENELITIAN}

Metode penelitian yang digunakan untuk mencari jawaban terhadap pengaruh modifikasi pembelajaran dan motivasi terhadap keterampilan dasar lempar lembing menggunakan metode eksperimen. Eksperimen menunjukan kepada suatu upaya sengaja dalam memodifikasi kondisi yang menentukan munculnya suatu peristiwa, serta pengamatan dan interpretasi perubahanperubahanyang terjadi pada peristiwa itu yang dilakukan secara terkontrol (Ali, 2015; Sugiyono, 2012).

Dalam penelitian ini peneliti menggunkan one group pretest-posttes design. Pada desain ini dilakukan pretes postestuntuk mengetahui keadaan awal subjek sebelum diberi perlakuan sehingga peneliti dapat mengetahui kondisi subjek yang diteliti sebelum atau sesudah diberi perlakuan yang hasilnya dapat dibandingkan atau dilihat perubahannya (Sugiyono, 2013). Penelitian ini dilaksanakan di STKIP Pasundan Cimahi, j1. Permana No 32b, Kelurahan Citeureup Kota Cimahi. Pengambilan data dilakukan di Stadion Sangkuriang Kota Cimahi yang berjarak $\pm 1 \mathrm{~km}$ dari STKIP Pasundan Cimahi Yang terdiri dari 30 mahasiswa kelas control dan 30 mahasiswa kelas non kontrol.

Berdasarkan pada rumusan masalah yang telah dituangkan di bab 1, yakni peneliti ingin mengetahui bagaimana peningkatan hasil dan keterampilan gerak dasar lempar lembing maka dari itu kali ini peneliti akan menjabarkan mengenai teknik pengumpulan data yang digunakan 
untuk mengukur keterampilan dan hasil belajar. Untuk keterampilan peneliti menggunakan teknik pengumpulan data pretest postest dengan mengacu pada rubik kriteria keberhasilan atau indikator-indikator ketercapaian keterampilan lempar lembing. Berikut merupakan tabel butir-butir indikator tersebut: Kemudian untuk mengetahui keberhasilan peningkatan hasil belajar lempar lembing peneliti menggunkan rubik kriteria penskoran peningkatan hasil belajar yang menjadi pedoman peneliti dalam mengukur keberhasilan peningkatan hasil belajar mahasiswa. Berikut merupakan tabel kriteria keberhasilan hasil belajar lempar lembing putra dan putri:

\section{HASIL DAN PEMBAHASAN}

3.1 Hasil

Berikut merupakan data hasil penelitian secara keseluruhan pada tabel 1:

Tabel 1. Deskripsi data Hasil dan Keterampilan Lempar Lembing

\begin{tabular}{lccc}
\hline & N & Mean & $\begin{array}{c}\text { Std. } \\
\text { Deviation }\end{array}$ \\
\hline Tes Awal Keterampilan Dasar Lempar Lembing Kelompok A & 30 & 20,5 & 3,00287 \\
\hline Tes Akhir Keterampilan Dasar Lempar Lembing Kelompok A & 30 & 22,4667 & 2,23966 \\
\hline Tes Awal Hasil Lempar Lembing Kelompok B & 30 & 19,4667 & 3,41127 \\
\hline Tes Akhir Hasil Lempar Lembing Kelompok B & 30 & 21 & 2,27429 \\
\hline
\end{tabular}

Setelah dilakukan uji normalitas dan homogenitas data, maka langkah selanjutnya adalah pegujian hipotesis. Uji tersebut dilakukan untuk menghasilkan kesimpulan dari permasalahan penelitian. Dalam menguji data hasil tes awal dan tes akhir untuk mengetahui pengaruh perlakuan disetiap kelompok dilakukan dengan paired sample t-test.

1. Pengaruh Modifikasi Pembelajaran Bola Berekor Terhadap Keterampilan Lempar Lembing.

Tabel 2. Paired Samples Test

\begin{tabular}{|c|c|c|c|c|c|c|c|c|c|}
\hline & & \multicolumn{5}{|c|}{ Paired Differences } & \multirow[t]{2}{*}{$\mathrm{T}$} & \multirow[t]{2}{*}{$\mathrm{df}$} & \multirow{2}{*}{$\begin{array}{c}\text { Sig. } \\
\text { (2- }\end{array}$} \\
\hline & & \multirow[t]{3}{*}{ Mean } & Std. & $\begin{array}{c}\text { Std. } \\
\text { Error }\end{array}$ & \multicolumn{2}{|c|}{$\begin{array}{c}95 \% \text { Confidence } \\
\text { Interval }\end{array}$} & & & \\
\hline & & & Deviation & Mean & \multicolumn{2}{|c|}{ of the Difference } & & & tailed) \\
\hline & & & & & Lower & Upper & & & \\
\hline Pair & pretest1 - & \multirow{2}{*}{$-3,69067$} & \multirow{2}{*}{5,50086} & \multirow{2}{*}{1.00431} & \multirow{2}{*}{-5.74472} & \multirow[b]{2}{*}{-1.63661} & \multirow[b]{2}{*}{$-3,675$} & \multirow[b]{2}{*}{29} & \multirow{2}{*}{.001} \\
\hline 1 & postest1 & & & & & & & & \\
\hline$\frac{\text { Pair }}{2}$ & pretest2 - &,- 99800 & 3,95095 & .72134 & -2.47331 & .47731 & -1.384 & 29 & .177 \\
\hline
\end{tabular}

Keterangan pada tabel 2 yaitu:

a. PAIR 1 (kelompok A pembelajaran lempar lembing menggunakan modifikasi alat)

Uji dilakukan dua sisi karena akan diketahui apakah rata-rata kelompok A sebelum dan sesudah adalah sama atau tidak. jadi dapat lebih besar atau lebih kecil, karenanya dipakai uji dua sisi. apakah uji akan dilakukan satu sisi atau uji dua sisi, dapat diketahui dari output SPSS yang menyebut adanya two tailed test. 
Kesimpulan:

$\mathrm{t}=-3,675$ dan sig $(\mathrm{p})=0,000<0,01$.

Ho: ditolak dan H1: diterima

Jadi: Pembelajaran lempar lembing dengan menggunakan modifikasi alat bola berekor berpengaruh terhadap keterampilan gerak dasar lempar lembing mahasiswa STKIP Pasundan Cimahi.

b. PAIR 2 (kelompok B pembelajaran lempar lembing tanpa menggunakan modifikasi alat)

Uji dilakukan dua sisi karena akan diketahui apakah rata-rata kelompok B sebelum dan sesudah adalah sama atau tidak. jadi dapat lebih besar atau lebih kecil, karenanya dipakai uji dua sisi. apakah uji akan dilakukan satu sisi atau uji dua sisi, dapat diketahui dari output SPSS 20 yang menyebut adanya two tailed test.

Kesimpulan:

$$
\mathrm{t}=-1.384 \text { dan } \operatorname{sig}(\mathrm{p})=0,000<0,01 \text {. }
$$

Ho: ditolak dan H1: ditolak

Jadi: Pembelajaran lempar lembing dengan menggunakan modifikasi alat bola berekor tidak berpengaruh terhadap keterampilan gerak dasar lempar lembing mahasiswa STKIP Pasundan Cimahi.

2. Pengaruh Modifikasi Pembelajaran Bola Berekor Terhadap Hasil Belajar Lempar Lembing.

Tabel 3. Paired Samples Test

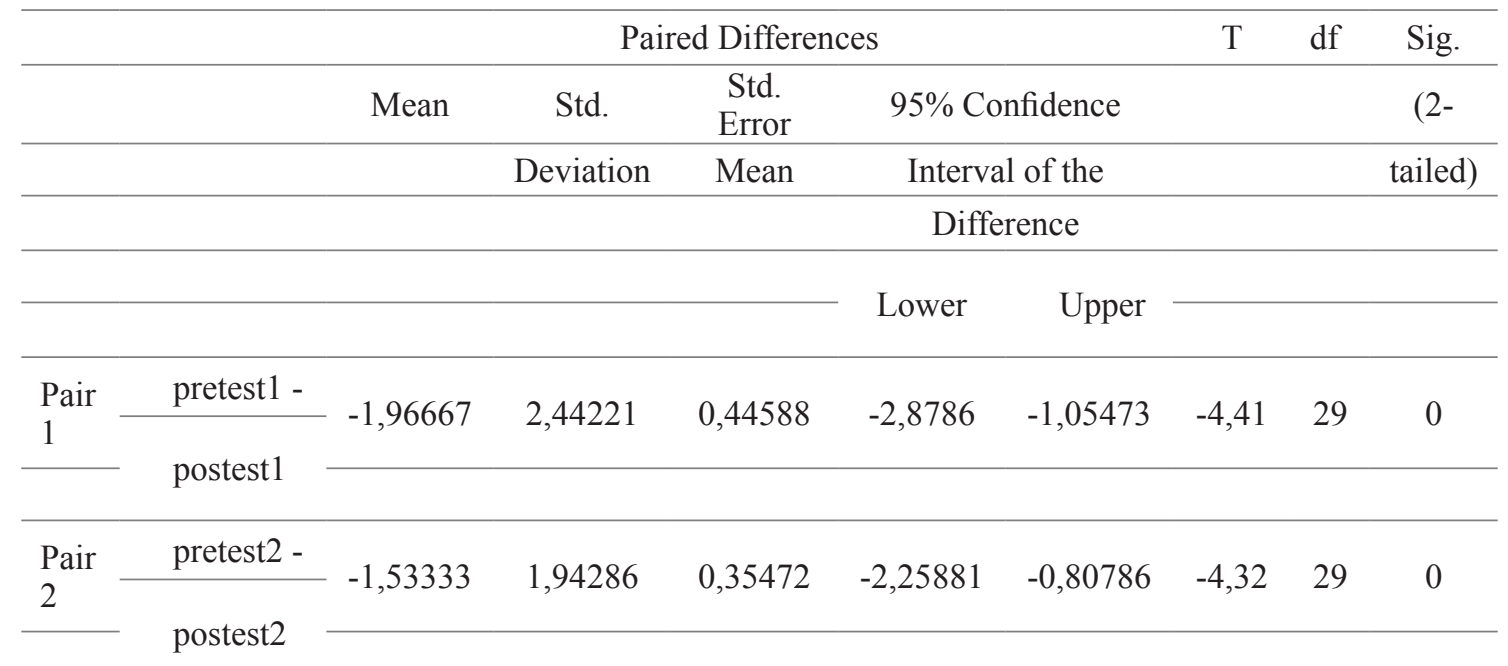

Keterangan pada tabel 3 yaitu:

a. PAIR 1 (kelompok A pembelajaran lempar lembing menggunakan modifikasi alat)

Uji dilakukan dua sisi karena akan diketahui apakah rata-rata kelompok A sebelum dan sesudah adalah sama atau tidak. jadi dapat lebih besar atau lebih kecil, karenanya dipakai uji dua sisi. apakah uji akan dilakukan satu sisi atau uji dua sisi, dapat diketahui dari output SPSS 20.

Kesimpulan:

$\mathrm{t}=-4,411$ dan $\operatorname{sig}(\mathrm{p})=0,000<0,01$.

Ho: diterima dan $\mathrm{H} 1$ : ditolak
Jadi: Pembelajaran lempar lembing dengan menggunakan modifikasi alat bola berekor tidak berpengaruh terhadap hasil belajar lempar lembing mahasiswa Stkip Pasundan Cimahi.

b. PAIR 2 (kelompok B pembelajaran lempar lembing tanpa menggunakan modifikasi alat)

Uji dilakukan dua sisi karena akan diketahui apakah rata-rata kelompok B sebelum dan sesudah adalah sama atau tidak. jadi dapat lebih besar atau lebih kecil, karenanya dipakai uji dua sisi. apakah uji akan dilakukan satu sisi atau uji dua sisi, 
dapat diketahui dari output SPSS yang menyebut adanya two tailed test.

Kesimpulan:

$\mathrm{t}=-4,323$ dan $\operatorname{sig}(\mathrm{p})=0,000<0,01$.

Ho: diterima ditolak dan H1: ditolak

Jadi: Pembelajaran lempar lembing dengan menggunakan modifikasi alat bola berekor tidak berpengaruh terhadap hasil belajar lempar lembing mahasiswa STKIP Pasundan Cimahi.

\subsection{Pembahasan}

Berdasarkan hasil penelitian dengan menggunakan modifikasi alat bola berekor ternyata dapat berpengaruh terhadap keterampilan gerak dasar lempar lembing dengan kata lain, latihan tersebut berpengaruh secara signifikan terhadap keterampilan gerak dasar lempar lembing dan bisa di pakai sebagai bahan pembelajaran lempar lembing yang memberikan pengaruh dalam penelitian ini adalah adanya kepuasan dalam proses pembelajaran sehingga timbunlnya partisipasi mahasiswa dalam melakukan proses pembelajaran. Kesimpulan di atas sesuai dengan teori bahwasanya modifikasi dalam mata pelajaran pendidikan jasmani diperlukan dengan tujuan agar: siswa memperoleh kepuasan dalam mengikuti pelajaran, meningkatkan kemungkinan keberhasilan dalam berpartisipasi, siswa dapat melakukan pola gerak secara benar (Yoyo, 2015; Rahyubi, 2012).

Jihad \& Haris (2009) menyatakan model pembelajaran dapat diartikan sebagai suatu rencana atau pola yang digunakan dalam menyusun kurikulum, mengatur materi peserta didik, dan memberi petunjuk kepada pengajar di kelas dalam mengatur pengajaran. Lebih lanjut Jihad \& Haris (2009) menyatakan model pembelajaran mempunyai empat ciri khusus yang tidak dipunyai oleh strategi atau metode tertentu, yaitu: (1) rational teoritik yang logis yang disusun oleh penciptanya, (2) tujuan pembelajaran yang akan dicapai, (3) tingkah laku mengajar yang diperlukan agar model tersebut dapat dilaksanakan peserta didik secara berhasil, dan (4) lingkungan belajar yang diperlukan agar tujuan pembelajaran ini dapat tercapai.

Berdasarkan hasil penelitian tanpa menggunakan modifikasi alat bola berekor ternyata tidak terlihat pengaruh terhadap keterampilan gerak dasar lempar lembing. Dengan kata lain, Pembelajaran tersebut kurang adanya latihan berulang-ulang. Latihan yang berulang-ulang ditujukan untuk meningkatkan keterampilan gerak dasar lempar lembing, maka peran dari bola berekor tersebut sangat diperlukan demi meningkatnya keterampilan gerak dasar lempar lembing.

\section{KESIMPULAN}

Berdasarkan hasil analisis data yang telah dilakukan maka kesimpulan dari penelitian ini sebagai berikut:

1. Pembelajaran lempar lembing menggunakan modifikasi alat berupa bola berekor memberikan pengaruh yang signifikan terhadap keterampilan gerak dasar lempar lembing di STKIP Pasundan Cimahi.

2. Pembelajaran lempar lembing tidak menggunakan modifikasi alat berupa bola berekor tidak berpengaruh terhadap keterampilan gerak dasar lembing di STKIP Pasundan Cimahi.

3. Pembelajaran lempar lembing menggunakan modifikasi alat berupa bola berekor tidak memiliki pengaruh terhadap hasil baelajar lempar lembing di STKIP Pasundan Cimahi.

4. Pembelajaran lempar lembing tanpa menggunakan modifikasi alat berupa bola berekor tidak memiliki pengaruh terhadap hasil lemparan lembing di STKIP Pasundan Cimahi. 


\section{DAFTAR PUSTAKA}

Ali. (2015). Pengaruh Modifikasi Pembelajaran dan Motivasi terhadap Keterampilan Dasar Sepak Bola. Majalengka.

Haryono. (2016). Meningkatkan Lempar Lembing Melalui Modifikasi Bola Berekor di SD N 08 Trans Merbang. Kalimantan Barat.

Hasan. (2014). Meningkatkan Hasil Belajar Kids Atletik Lempar Turbo Melalui Modifikasi Permainan Bola Berekor Bagi Siswa Kelas 5 SDN 1 Sukorejo Tahun Ajaran 2013/2014. Semarang: Universitas Negeri Semarang.

Hasan. (2015). Meningkatkan Hasil Belajar Kids Atletik Lempar Turbo Melalui Modifikasi Permainan Bola Berekor Bagi Siswa Kelas 5 Sd N 1 Sukorejo. Semarang: Universitas Negeri Semarang.

Jihad, A., \& Haris, A(2009). Evaluasi pembelajaran. Jakarta: Multi Pressindo.

Lamusu. (2011). Penerapan Model Pembelajaran Kooperatif Tipe Stad dalam Meningkatkan Hasil Belajar Lempar Cakram Pada Siswa Kelas V SDN No 59 Dumbo Raya Kota Gorontalo. Gorontolo: Universitas Negeri Gorontalo.

Lutan. (2015). Penerapan Modifikasi Alat Menggunakan Cakram yang di Modifikasi Pada Mahasiswa STKIP Pasundan Cimahi. Cimahi: STKIP Pasundan Cimahi.

Rahyubi, H. (2012). Teori-Teori Belajar dan Aplikasi Pembelajaran motorik deskripsi dan tinjauan kritis. Bandung: Nusa Media.

Rizky. (2013). Pengembangan Pembelajaran Lempar Lembing Menggunakan Media Roket. Semarang: Universitas Negeri Semarang.

Sobarna. (2017). Penerapan Media Visual Bergerak terhadap Hasil Belajar Lompat Jauh. Cimahi: STKIP Pasundan Cimahi.

Subari. (2013). Melalui Modifikasi Alat Pembelajaran dapat Meningkatkan Gerak Dasar Lempar Lembing pada Siswa Kelas V Di SD Negri 1 Sidodadi Asri Kecamatan Jati Agung Tahun Pelajaran 2012/2013. Lampung: Universitas Negeri Lampung.

Sugiyono. (2012). Memahami Penelitian Kualitatif. Bandung: Alfabeta.

Sugiyono. (2013). Metode Penelitian Kualitatif Kuantitatif dan $R \&$ D. Bandung: Alfabeta. Hal 3.

Sukadiyanto. (2008). Peranan Pendidikan Jasmani terhadap Perkembangan Otak. Makalah. SMAN 1 Yogyakarta.

Yoyo. $\quad$ (2015). Penerapan Modifikasi Alat Menggunakan Cakram yang di Modifikasi pada Mahasiswa STKIP Pasundan Cimahi. Cimahi: STKIP Pasundan Cimahi. 